\title{
Study on the College Chinese Teaching Model under the New Information Environment
}

\author{
Shuhong Sun \\ Changchun Vocational Institute of Technology, Changchun, China \\ sunshuhongcc@126.com
}

Keywords: New information environment; College Chinese language and literature; Teaching mode.

\begin{abstract}
College Chinese is an important public compulsory course in our country's higher education curriculum system, and plays a significant role in improving humanities accomplishment of college students. However, there are many problems in the traditional pattern of College Chinese teaching, for example, College Chinese teaching efficiency and quality are not effective. With the development of information technology, network environment provides a new perspective for the College Chinese teaching. This paper briefly analyses shortcomings in the course of traditional College Chinese teaching mode, the reform and practice of College Chinese teaching mode under the new information environment.
\end{abstract}

\section{Introduction}

The rapid development of modern information technology with multimedia and network at the core has provided an idea of teaching platform and environment for course teaching. Currently, how to build a new teaching model under the network environment has been an issue of great concern to every educator. As a course oriented towards cultivation of cultural qualities in China, College Chinese plays a critical role in improving college students' Chinese language accomplishment and applied ability, and carrying forward Chinese national culture. However, over the past few years, teaching models of College Chinese in China have revealed many problems, which necessitates the construction of a brand-new College Chinese teaching model under the network environment.

\section{Influence of the New Information Environment on College Chinese}

\subsection{Diversification of teaching objectives}

The development of teaching models based on new information technology has brought earth-shaking changes to traditional educational concepts. Institutions of higher education are expected to establish educational values oriented towards all-around development of students, adhere to educational principles and talent growth principles, study students' differences, respect students' right to choose on their own, and encourage students to develop their specialties. To the end, they need to continuously deepen the talent development model reform and the educational system reform, and explore diversified and personalized development of students ${ }^{[1]}$. According to the requirements of talent development in colleges and universities, students' independent learning ability and ability to put their knowledge into practice, namely analysing and solving real-world problems with their knowledge, are at the core.

\subsection{Diversification of knowledge source}

The application of the maximum advantage of new information technology to the educational field lies in the integration of quality teaching resources scattered in different spaces and periods to realize all-people sharing of quality educational resources. Either courses given by famous lecturers in key domestic colleges or quality courses given by first-class colleges at the other side of the ocean-all these courses can be integrated to the same resource platform via the network. Thanks to 
emergence of new information technology, the source and scope of teaching resources can be maximally extended. Teachers and students can conveniently acquire all kinds of teaching information as long as they have access to the Internet. The breakthroughs of space and time limitations have brought great convenience to learners, which can accelerate expansion of quality teaching resources and satiate urgent needs of society and citizens for high-quality education ${ }^{[2]}$.

\subsection{Popularization of mobile learning}

New information technology has made time and space no longer a barrier for teaching activities. Currently, audio-visual transmission technology and online learning system have freed limitations of time and space in learning. Teaching activities can undergo in any place and at any time. Mobile learning is a kind of ubiquitous learning for learning subjects continuously on the move and with unfixed learning time and space. Either learners are in the classroom or in the library or in the restaurant or in the station or lying on the bed or walking, mobile networked equipment can be used for learning. To sum up, learning activities are happening in any place and at any time.

\section{Problems Existing in the Traditional College Chinese Teaching Models}

\subsection{Marginalization of College Chinese}

A large number of students in higher vocational colleges superficially think that professional knowledge and skills are the linchpin to future employment ${ }^{[3]}$. To them, College Chinese is not that important, and taking College Chinese courses is only to grab adequate credits. Some leaders and teachers in vocational colleges also agree that College Chinese is not a core course, which can be either taken or not taken. The attention paid to arrangement of class hours and faculty arrangement for College Chinese is insufficient. These subjective and objective factors have, to a large extent, restricted a full play of College Chinese, seriously impairing the attractiveness of relevant courses.

\subsection{Lack of unification among College Chinese textbooks}

There have not yet been any unified standards guiding how colleges and universities should choose textbooks for College Chinese. This has, to some extent, resulted in inundation of Chinese textbooks in college. Different versions of College Chinese textbooks are uneven in their quality. Some even copy the content from each other or are casually pieced together, which seriously weakens the cultural connotation and interestingness of College Chinese. Therefore, many college students deem College Chinese textbooks boring to read, which is even truer to higher vocational colleges.

\subsection{Unification of College Chinese teaching methods}

As a course of general education, College Chinese covers a rich content, ranging from basic language skills to how to be a decent man. However, the traditional theoretical teaching methods still dominate in class. Most teachers impart knowledge points in textbooks to students via spoon-feeding, chalk plus blackboard, and other mechanical ways. The teaching content is boring; the lecturing forms lack diversification; the teaching methods are not novel; the teaching methods and teaching content are limited. As these problems remain, college students can hardly develop interest in learning College Chinese. Meanwhile, the "de-Chinese" phenomena in College Chinese teaching activities are worrying. In terms of the traditional, boring and unified lecturing forms, some young teachers rely on multimedia equipment too much. In class, video display replaces teachers' knowledge imparting. Though the fun of College Chinese courses can be thus increased, the role of College Chinese in promoting language communication is lost, which is a heart-wrenching fact.

\subsection{Weak faculty resources for College Chinese}

Payment of College Chinese teachers in China is still low, and the room for their further development is limited. As a result, College Chinese lecturers usually change their jobs, and their literature accomplishment is uneven. Generally, most College Chinese lecturers lack 
professionalism, who can hardly provide correct guidance for students in the process of teaching. Without adequate teaching experience, they usually fail to create an active class atmosphere to spark students' interest in learning. Consequently, the teaching effect is far from being satisfactory. Meanwhile, most College Chinese teachers are not fully committed to College Chinese teaching. Therefore, they devote little time and energy to exploration and innovation of teaching content, teaching methods and teaching objectives, which is a major reason for the declining teaching quality of College Chinese ${ }^{[4]}$.

\section{Construction of the College Chinese Teaching Model under the New Information Environment}

\subsection{Integration and utilization of informationalized teaching resources}

Teachers can combine teaching cases, videos, courseware, films, music and other resources of the kind with corresponding knowledge points to achieve a more thorough application and analysis during the teaching process. These teaching resources can also allow them to summarize the teaching content and introduce knowledge points to students more vividly, which can not only arouse students' passion for learning, but also help students deepen their understanding of knowledge points and actively participate in classroom activities. Moreover, teachers can form their own teaching style, which can attract more students to attend their Chinese courses.

\subsection{Emphasis on cultural course construction and improvement of the dual-wheel-driven curriculum system}

Course teaching and professional construction should be closely combined. The focus should be on the cultivation of students' basic qualities, general abilities and cultural accomplishment required by different trades. In other words, College Chinese should endow students with the notion of "Mass Chinese", thus promoting integrated, scientific and systematic reform of the cultural education. Meanwhile, more attention should be paid to reasonable arrangement of course content and strengthening of students' cultural accomplishment. During the practical process of teaching, teachers should teach basic cultural knowledge to students. However, the improvement of vocational abilities is a more important goal of College Chinese. According to these two goals, a dual-wheel-driven curriculum system with vocational cultural accomplishment and general vocational abilities at the core can be put in place.

\subsection{Establishment of a network-aided teaching platform}

Through network-aided teaching, students can deepen their understanding of College Chinese courses, and acquire more knowledge accommodating to their personalized development. On the other hand, the network-aided teaching platform can be used to search references via information retrieval. In this way, students can obtain information necessary to their study and research. This is also a process in which their ability to convey, process and use information can be fully honed. The rich network resources will definitely facilitate students' thematic research under the network environment. Teachers can also build the network boutique course library and literature blog to promote joint participation of teachers and students in College Chinese teaching activities.

\subsection{Adoption of a scientific assessment}

Under the new information environment, teachers can make use of various computer, multimedia and modern teaching methods to assist in their making of teaching courseware, preparation of playlets to large-scale College Chinese thematic activity. Diverse competitions are effective methods to stimulate scenario teaching and classroom teaching. By participating in competitions, students' learning potential and enthusiasm for learning College Chinese can be maximally tapped ${ }^{[5]}$. Teaching administration department and Chinese teachers can develop a complete Chinese learning assessment system according to the examination outline and practical situations. The assessment methods should be operational, and the assessment styles should be diversified. Apart from assessing comprehensive understanding of students and their ability to use Chinese, the 
assessment system should also investigate students' reading and understanding of Chinese masterpieces. Besides, students' participation in College Chinese related activities should take up a higher proportion in the assessment result, with the proportion of the classroom written examination reduced, which can also further increase students’ activeness in learning College Chinese.

\section{Conclusion}

To sum up, College Chinese teaching is faced with various challenges under the new information environment. Colleges should build a brand-new College Chinese teaching model following a student-oriented mentality. By making use of college students' familiarity with the Internet and we-media, colleges can increase college students' awareness of autonomous learning of College Chinese. Meanwhile, College Chinese teachers should also update their teaching concepts by engaging in teaching activities under the network environment with a positive mentality. Apart from effective integration of the teaching content, College Chinese teachers can seek improvement and optimization of relevant teaching methods. In this way, College Chinese teaching activities can better combine comprehensive ability development, knowledge imparting and innovation of students to effectively improve students' comprehensive qualities.

\section{References}

[1] Lin. S. On construction of the College Chinese course online teaching platform [J]. China Adult Education, 2015 (7).

[2] Chen. C. Y. College Chinese new teaching model construction under the multimedia network environment [J]. Education and Vocation, 2008 (6).

[3] Zheng Q. Building an applied Chinese teaching model for higher vocational colleges [J]. Journal of Xuzhou Normal University (Educational Sciences Edition), 2010 (4).

[4] Chen C. J. Application of multimedia to Chinese teaching models [J]. Learning Weekly, 2014 (13).

[5] Li X. H. College Chinese teaching against the backdrop of "sinology fever" [J]. Theory Learning, 2011 (11). 